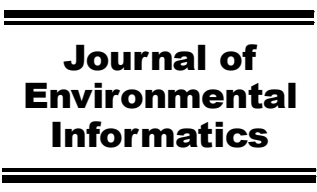

Www.iseis.org/jei

\title{
An Ecosocial Climax Model Based on Concepts of Climax Community for Analyzing Communities in Silas Marner to Ensure Protection of Ecosystem
}

\author{
N. Y. Zhou* and L. C. Li \\ College of Foreign Languages and Cultures, Xiamen University, Xiamen 361005, China
}

Received 22 April 2018; revised 03 January 2019; accepted 15 June 2019; published online 17 April 2019

\begin{abstract}
In this study, a theoretical model of ecosocial climax is developed to evaluate human community in order to ensure efficient protection of ecosystem. Unlike previous works that emphasize analysis of nature, the present model is based on such ecological concepts as ecological chain and climax to analyze the problems of ecosocial system. The proposed model is used to compare the two ecosystems in George Eliot's Silas Marner: the ecologically problematic community of Lantern Yard, and the ecologically sustainable community of Raveloe community. The result shows that governed by check and balance, negotiation and concession, morality and mutual contract, and rule of law, Raveloe is a climax community that encourages equality, interaction and exchange, adaptability and tolerance, diversity and wholeness, dynamic stability and sustainable development. It is shown that George Eliot's ideal society is one of ecological social order with harmonious human relationships formed in humble reconciliation with nature in fear of God so that humans do not pose as threat to the equilibrium of nature. Hopefully, this interdisciplinary research might prove helpful to analysis of social problems in human society to contribute to reconciliation between humans and nature.
\end{abstract}

Keywords: climax community, ecocriticism, ecofeminism, ecosocial criticism, ecological niche, ecosocial climax

\section{Introduction}

As an interdisciplinary study of the relationship between literature and the environment conducted in a spirit of commitment to environmentalist praxis (Buell, 1995), ecocriticism originated in part from ecologism or environmentalism that features reflection on and criticism of humanism. It criticizes anthropocentrism for its hierarchy of inequality that puts man in dominating position above nature, since anthropocentrism holds that humans are the central and most important entities in the world while nature and all other beings are means to human ends. Although some critics try to redefine anthropocentrism and believe that it can be a powerful motivation for environmental protection since humans working out of legitimate human interests can exert positive environmental impacts, there is a stronger insistence that it essentially indicates human focus on themselves at the risk of the planet (Zhang et al., 2017; Kopnina, 2018).

By contrast, ecocriticism takes an earth-centered approach to literary studies (Glofelty et al., 1996). It examines the various ways literature represents nature, illustrates environmental concerns, especially about the negative impact of human be-

\footnotetext{
* Corresponding author. Tel.: +86 592 2183637; fax: +86 5922182476.

E-mail address: nyzhou@xmu.edu.cn (N. Y. Zhou).
}

ISSN: $1726-2135$ print/1684-8799 online

(C) 2020 ISEIS All rights reserved. doi:10.3808/jei.201900422 haviors on the planet (land, water and soil) and on other nonhuman life forms (animals and plants etc.), and is committed to "effecting change by analyzing the function - thematic, artistic, social, historical, ideological, theoretical, or otherwise - of the natural environment, or aspects of it, represented in documents (literary or other) that contribute to material practices in material worlds" (Estok, 2005). It extends such humanistic values as equality and justice to the natural world, emphasizing that all its non-human parts are equal to and in relationship with humans, and should be included in ethical concerns. Under the influence of ecologism, humanism turns away from anthropocentrism to ecological humanism, or even to "non-anthropocentric humanism" (Zapf, 2008). In this process, reconciliation is achieved between humanism and ecologism (Wang, 2006). However, since ecocriticism focuses essentially on the relationship between humans and the natural world for protection of nature, it tends to overlook the problems of human society itself.

Ecofeminism, a term first used by Francoise d'Eaubonne in 1980 (Mies et al., 1993), much earlier than the first use of "ecocriticism" (Buell, 1995; Glotfelty et al., 1996), is more broad-minded than the latter, as is shown in Figure 1. It not only considers the importance of building a harmonious relationship between humans and nature as ecocriticism does, but also associates domination of women by men with the domination of nature by culture, in that there is physiological and psychological homogeneity between women and nature, both being "the other" oppressed by patriarchy (King, 1989). It promotes estab- 


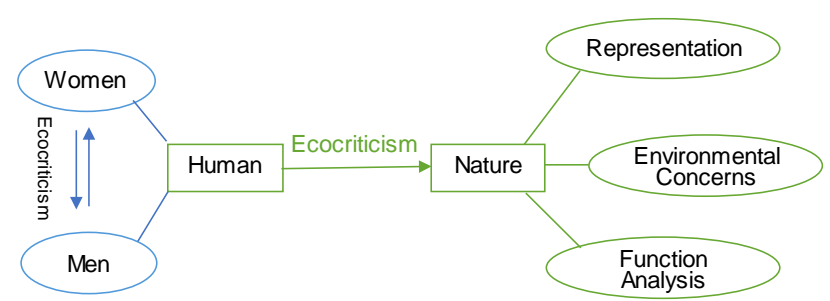

Figure 1. Ecofeminism and ecocriticism.

lishment of harmonious relationship between men, women and nature. However, although ecofeminism deconstructs the binary opposition of men and women, its focus on the close relationship between women and nature leads to a new dichotomy between women and nature on the one hand, and men on the other hand. In an even worse case, the burden of liberating women and saving nature from exploitation and destruction is shifted solely on women (Stephens, 2013). In addition, although ecofeminism tries to include all other subordinate groups oppressed by patriarchy and relates them all to oppresssion and domination of nature, it essentially holds that harmony between the two genders will eventually bring about harmony between humankind and nature (Nangong et al., 2011), ignoreing various other marginalized groups, and ultimately ambiguous about how to establish harmonious relationship among individuals, groups, or communities and between humans and nature.

Ecological ethics holds that the relationship between humans and the natural world is the refraction or extension of human relationship. To a certain degree, almost all ecological problems stem from social issues (Bookchin, 1993). Detailed and scientific research and works in the field of environment science demonstrate not only strong awareness of the negative impact on ecosystem made by socioeconomic activities, but also practical solution through land use management (Chen et al., 2013; Tong et al., 2015; Xie et al., 2019), water management and policies (Huang et al. 2000, Ly et al., 2010; Su et. al., 2013; Yang et al., 2014; Pastori et al. 2015), pollution management (Huang et al. 2006; Ding et al., 2017), air quality management (Woo, 2016), governance network structure (Folke, 2005; Manolache et al., 2018), etc.

An authentic and effective nature-centered approach, therefore, is to develop ecocriticism or ecofeminism into ecosocial criticism that not only extends humanistic concerns and ethical thinking to the ecological world, but also learns from nature to seek ways to make sense of cultural and social problems, to contribute to a harmonious human relationship and reconciliation between humans and the natural world. This is echoed in the functional approach of the cultural ecology branch of ecocriticism, which seeks to find and analyze the analogies between ecosystems and cultural process brought out through the medium of literature which in its turn potentially serves to revitalize the cultural system (Zapf, 2008).

In recent surge of interest in ecocritical scholarship in the Victorian field, critics give prominence to a Victorian ecocriticism attentive to Anthropocene concerns, aiming to evaluate how literature represents and theorizes the ecological consequence of human economy, "to draw analogies between scientific representations of earth systems (climate models, ecological microcosms) and literary artifacts; and to understand the fashioning of a 'simple life' away from damaged industrial spaces" (Williams, 2017). These efforts demonstrate the necessity not only to tackle moral questions in human interactions with nature, but also to adjust human relationships and human society itself in light of ecology and environment science, to lead to efficient protection of nature.

This is feasible all the more because natural ecosystem has much in common with social ecosystem, as shown in Table 1. First, biological species and population structure of natural ecosystem correspond to individuals, groups and communities of various kinds and their structuring in social ecosystem. The inorganic environment where organisms live, such as soil, water, climate, etc., corresponds to the political and economic culture of social ecosystem. Organisms need suitable ecological environment for their growth, and people also need good social environment for their development. Second, an organism or a population has its niche, which includes habitat (physical environment, a place in the ecological network, and the period of time when it is active), resources it could use, and interactions with others (Chase et al., 2003). Likewise, in social ecosystem, different individuals, communities or groups also have their respective ecological niches in the social ecological network. They need to have social resources and living space, and maintain certain relationships with the surrounding individuals and communities. This social niche covers concepts such as rights, interests and identity, involving political, economic, spiritual, and emotional factors. Third, through ecological succession over time, organisms and species populations in the biotic com-

Table 1. Climax Community: Nature and Human Society

\begin{tabular}{lllll}
\hline & Biodiversity & Adaptation to environment & Ecological niche & Other features \\
\hline $\begin{array}{l}\text { Natural } \\
\text { Ecosystem }\end{array}$ & $\begin{array}{l}\text { Biological species, } \\
\text { population structure, } \\
\text { ecological network }\end{array}$ & $\begin{array}{l}\text { Inorganic environment (soil, } \\
\text { weather, climate, etc.) }\end{array}$ & $\begin{array}{l}\text { Habitat, } \\
\text { resources, } \\
\text { interactions }\end{array}$ & $\begin{array}{l}\text { Dynamic balance, } \\
\text { stability, } \\
\text { energy flow }\end{array}$ \\
Social & $\begin{array}{l}\text { Networks of individuals, } \\
\text { Ecosystem } \\
\text { (ethnicity, race, religion, } \\
\text { class/occupation, gender, } \\
\text { culture) }\end{array}$ & $\begin{array}{l}\text { Social environment } \\
\text { (political, economic, } \\
\text { spiritual, emotional) }\end{array}$ & $\begin{array}{l}\text { Ecosocial niche } \\
\text { (social resources, } \\
\text { and living space, } \\
\text { etc. ) }\end{array}$ & $\begin{array}{l}\text { Balance, sustainable } \\
\text { development, } \\
\text { exchanges }\end{array}$ \\
\hline
\end{tabular}


munity achieve active equilibrium and form a relatively steady community best adapted to local climate and soil conditions. This can be considered a climax community, and its characteristics mainly include diversity of species, correspondence to environmental conditions, wholeness and dynamic balance among species populations, relative stability and sustainable development (Whittaker, 1953). Although the climax theory is still a matter of ecological debate and research (Li et al., 2006), and that "succession was highly variable, and that it did not always end in a climax formation" (Van der Valk, 2014), it can be illuminating for investigation of the literary world and even the human world. In light of a climax community, an ecosocial climax can be achieved where a healthy ecological social and ethical order is established.

The objective of this paper, therefore, is to establish an ecosocial climax model that can be used in ecosocial criticism in literature, based on concepts of climax community for analyzing human communities to ensure protection of ecosystem, as shown in Figure 2. In this ecosocial climax, individuals, various communities or social groups, intersectioned with class/ occupation, ethnicity, race, religion, culture and gender etc., enjoy a state of relative stability and sustainable development as part of and in harmony with nature in a nature-centered ecosystem, guaranteed by equality, tolerance and inclusiveness of the social environment; complexity and diversity; mutual contract, check and balance, governed by Law of Nature, morality and legislation, with internal mobility and external interactions and value exchanges. With Silas Marner as a case study, this paper not only examines nature with humanistic concerns to achieve reconciliation of humanism with ecologism in nature, but also adopts such ecological concepts as biological chain, succession and climax community, and ecological niche to make comparison between the two communities described in the novel. This will ultimately reveal George Eliot's unique ecological vision about the problems of society and about how to establish an ecological social order to achieve coordination between humans, which will lead to reconciliation of humans and nature. Edwin Fairley examines Silas Marner's structure, character delineation, humor, and moral sense, maintaining that it presents the art of George Eliot at its best (Fairley, 1913). However, although studies have been done with regard to Eliot's ecological awareness (Henson, 2011; Hardy, 2014; Paxton, 2014;

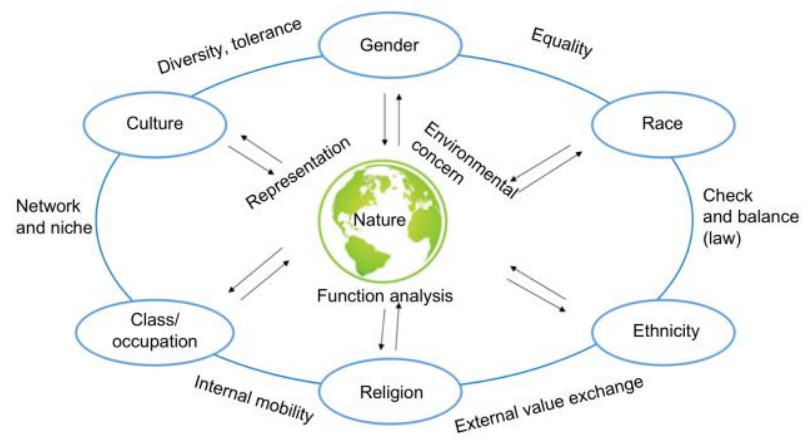

Figure 2. Ecosocial Climax.
Williams, 2017; Mazzeno, 2017), so far nothing similar to what this paper proposes has been done yet.

With the ecosocial climax model, this study develops an ecosocial criticism that throws new light on what William Rueckert suggests the application of ecology and ecological concepts to the study of literature (Glotfelty et al., 1996), not only providing a new perspective for the theories and practices of ecocriticism and ecofeminism, but also contributing to improved understanding of the dynamics of social system in real world. It is acknowledged that study of literary works from environmental perspective expands the scope of the science of environmental study with its self-reflexive staging of complex life processes (Zapf, 2008; Zhang, 2017), but this study will also show the fruitful collaboration and inalienable connection between science and culture.

\section{Ecological Network, Ecological Niche, and Principles of Equality}

The idea of biological chain, or ecological network, rather than biological pyramid/hierarchy, is fundamental to a climax community, and involves two concepts. The first is equality, which means that each link in the ecological network is given a more equal consideration. One missing link might lead to breaking up of the biological chain and put the entire ecological network out of existence. The second is the importance of the individual. It means that each organism in each link is entitled to its ecological niche. This thinking pattern also applies to ecological network of society. First, as ecofeminism points out, each individual or community is an integral part of the social structure. They should be treated equally rather than being considered in terms of class or hierarchy that features inequality and discrimination (Oppermann, 2013). Secondly, each individual, community or group is both interdependent with others and indispensable in itself. One missing component may cause consequences, or lead to breaking of social chain or even the entire social network. Since each life is valuable, they should have their own ecological niche to achieve self-identification and to realize their potential. The idea of ecological network can subvert and displace the thinking pattern of hierarchy in social structure.

In Silas Marner, Silas is a part of the ecological network in the emerging industrial Lantern Yard community. However, that ecosystem is in poor conditions and deprives Silas of his socio-ecological niche, as shown in Table 2. Above all, the industrial Lantern Yard is far from nature, and its social environment is characterized by conspiracy, treachery, plunder and violence rather than light as its name indicates. While it advocates piety and believes in God's calling, God's choice, and assurance of salvation, its piety is exploited to cover crimes. Silas is framed and declared guilty of murder and theft by casting of lots in the name of submitting to the will of Heaven. As for his social position, Silas finally finds himself at the very bottom of social ladder. If resources in an ecological niche represent metaphorically several aspects for a person to survive and develop in a society, Silas has almost none: except for his craft 
Table 2. Ecological Niche versus Socio-ecological Niche in Lantern Yard

\begin{tabular}{lll}
\hline Ecological niche & & Silas' Socio-ecological niche in Lantern Yard \\
\hline Habitat & Physical environment & Social environment of conspiracy, treachery, plunder, and violence \\
& Place in network & Bottom of social ladder in society \\
& Period of time & Temporary residence \\
Resources & Food, and nutrient for survival & Economically secure \\
& and development & Physically weak \\
& & Intellectually near nobody \\
& & Spiritually without faith \\
Interactions & Species and & Abandonment of fiancée \\
& community & No friends or neighbors \\
\hline
\end{tabular}

that brings him economic security, "physically he was weak, he had near-sight, and was subject to cataleptic fits: intellectually he was as near nobody as he could well be; and spiritually he had lost what narrow faith he once had" (Fairley, 1913). As for interaction with others, he is emotionally isolated, his friends turned into enemy and his fiancée abandoning him. And his sojourn here is temporary. He is forced to leave, drifting in the wilderness, and "descents into alienation and hatred because he cannot resign to what appears to be the existence of evil in the world" (Nassiri et al. 2016). In ecological terms, his alienation and hatred are the consequence of a man robbed of his niche to develop or even to survive in an ecosystem where ecological balance is disrupted.

Silas's exile represents a missing link in the ecological chain in the Lantern Yard community so that it eventually disappears, replaced by a factory, a dark, ugly, and stinking place. This becomes a socio-ecological metaphor of industrial dystopia: excessive desires or violent plundering of resources inevitably infringe on the living space and interests of others, break up various social relations, disrupt social balance, and cause deterioration of socio-ecological environment. The entire community might lose its stability, and eventually turn into chaos and ultimately extinct.

The counterexample of Lantern Yard is the Raveloe community. Both ecosystems involve Silas Marner. However, while Silas loses his ecological niche in the Lantern Yard community, his history is intersectioned with the life of Raveloe that features diversity of individuals, groups and class/social roles.

\section{Ecological Succession, Diversity, and Principles of Adaptability and Tolerance}

Essential to a climax, an ecological network must necessarily be biodiverse, developed through ecological succession. With changes in the species structure of an ecological community over time, ecological succession features replacement of individuals or old species of cenopopulations, and more or less orderly development of its environment and its structure. While succession may occur "as a highly variable and irregular change of populations through time, lacking orderliness or uniformity in detail", it can be fundamentally marked by certain fairly uniform overall tendencies (Whittaker, 1953). Some systems might develop gradually and steadily through ecological succession towards a biodiverse system of climax formation. The more diverse the species are, the more complex the populations are; the more complex the structure, the more stable and capable of self-perpetuation the climax is.

Likewise in a certain society, cultural elements, groups or communities constantly undergo adjustments and development; and with absorption of incoming groups or cultural elements, its culture might undergo internal adjustment and progressive development. Succession and climax theory lends support to the proposition of ecofeminism that the social composition of a society should be pluralistic, heterogeneous, and multi-layered (King, 1989), but more importantly, it also emphasizes that individuals, various groups or communities, of different ethnicity, race, class/occupation and gender, etc., grow and develop in interdependence, and in check and balance to form a relatively stable human climax. Homogeneity is not conducive to social stability.

From the perspective of ecology, Silas Marner tells about how an outsider migrates into a community, and is gradually integrated into it, promoting healthy evolution of the community. In the beginning, Silas appears as an outsider, an alien, isolated in a stone house in the outskirts of the Raveloe community. And this Silas represents the beliefs and values of industrial society. Money and the weaving loom from the industrial world provide him a false sense of security and identity so that he is completely alienated from the villagers, living a dead life.

Contrary to the city that represents desolation and destruction, the Raveloe community is located in a fertile plain and represents countryside not yet polluted or damaged by the industrial revolution. Whether Silas is accepted or not by the Raveloe community depends both on its tolerance of outsider and on whether Silas himself is willing to adapt to it. Like the soil microbes in plant rhizosphere - the soil nearest to the plant root system, Silas inhabits the area, albeit marginal, around the plant of Raveloe. The interactions between Silas and Raveloe resemble those between the soil microbes and the host plant. Raveloe, like a plant with resistance mechanisms against danger and threat (Nihorimbere, et al. 2011), is not defenseless. Its initial response to Silas the stranger is curiosity, suspicion, but gradually it is accustomed to his presence. On Silas's part, Raveloe functions as his host community, his life support system since he earns a living on weaving in that community. In 
his association and interactions with the community, he needs to attain properties identical or similar to his host community before he can be identified as one of its members.

The process of tolerance, adaptation and acceptance takes a long time. Silas gradually becomes more and more "identical" with the Raveloe community by taking on the physical and chemical attributes of his "habitat" or environment. The turning point of the change is the robbery of his gold, symbolizing that his fake identity starts to break down. And the key to this change is his adoption of Eppie, who replaces his gold coins and with her, Silas "redeems himself as a social being" (Karl, 2007). While the gold coins he earns mostly from the upper class of the community bring him no real communications, he is able to have real interactions with the grass roots in the Raveloe community. The baby girl "elucidates for Silas how the links between individuals within the community are constructed around 'need' - both economic and emotional" (Berger, 2000). She makes it possible for Silas to find his real identity and home in the villagers, which are more important than economic establishment for one to live a fuller life.

As for Raveloe, like the roots of a plant that release large quantity of metabolites, acting as chemical signals for soil microbes to move to the root surface, thus creating a niche for microorganisms to colonize the rhizosphere (Nihorimbere et al., 2011), the villagers are willing to help and create a niche for the desperate Silas. When he adopts Eppie, they recognize his similarities with them. They are like the plant root system for the Raveloe community, releasing good human qualities, signaling for the alien Silas to move to them and to adhere to them.

With adaptability of outsiders and inclusiveness of the community, Raveloe forms a sharp contrast to Lantern Yard in ecosocial diversity, as shown in Table 3. Surely Eliot's different treatments of the two communities contribute to this contrast. When describing the city in which Lantern Yard is located, Eliot adopts fast-paced narrative and devotes only 10 pages of the novel to the place, describing no more than 8 male and female characters there, including Silas. When Silas revisits it, Lantern Yard has perished, and the city becomes a noisy place with strange and indifferent people. The socio-ecological environment of Lantern Yard is cramped, somber and homogeneous. By contrast, Eliot's omnipotent perspective to Raveloe, which takes up 175 pages, presents it as a complex structure with 12 groups, 51 individual men and women who have 3 ways of religious faith, encompassing 17 social roles, strata and occupations. This contrast reflects Eliot's affirmation of the latter community and disapproval of the former one. If Lantern Yard deprives Silas of his ecological niche, Raveloe creates niche for outsiders like Silas, with at least 6 people incoming versus 1 in the former. It is a climax of tolerance, inclusiveness and diversity.
This perspective helps us understand incoming cultures (groups). Cenopopulations in the natural world develop adaptations to environmental conditions. Similarly, incoming groups try to find ways to adapt to local culture. On one hand, foreign culture and local culture are not in opposition. Instead of becoming "invasive organism" destructive to the local culture, incoming culture seeks mutual ground and universal values, establish interactions and communications, and make contributions to the development of local culture. On the other hand, local culture allows the existence of multicultural elements and groups, accepts contribution from incoming cultures and constantly absorbs new nutrients to promote a stable development and renewal. In short, in ecological terms, human society should create an environment conducive to a climax of complexity, diversity, and sustainable development.

\section{Wholeness and Principle of Dynamic Balance}

Diversity and complexity in an ecosystem need organization and order to prevent it from degenerating into chaos and to keep it a whole. In the case of a climax, wholeness means that the species and cenopopulations form a biological web featureing dynamic balance (Clements, 1936): it is relatively stable, and the species or populations are interdependent, and mutually constrained. Similarly, in a society like Raveloe, various individuals, groups or communities are related to each other in a state of check and balance with regard to rights and interests, and they become an organic whole. Here, tolerance and acceptance form a binary unity with order and constraint.

Raveloe is in good order with various individuals, groups and communities playing their respective roles and performing their duties. There are clearly some laws sustaining and regulating the community in order. Nassiri et al. interpret the novel from Kierkeggard's notion of three spheres of existence, namely aesthetic, ethical and religious, noting that "[i]f the aesthetic is the lowest ladder in the existence of an individual who can fluctuates between the mean decadence to the highest sense of beauty peppered with the main elements of pleasure and enjoyment, the ethical requires to drift in the realm of universal laws and social mores which is in stark contrast to religious existence. The religious person contravenes the moral conventions of his society and is only accountable to God." (Nassiri et al. 2016). If Kierkeggard's aesthetic sphere refers to a life both governed by sense, impulse and emotion, and of sublimation of the senses into imaginative realm, it can only be part of life. The pleasures of sensual and aesthetic life can be the energy drive to living a happy life, like in the case of Eppie and Aaron among loving family and neighbors in nature, as opposed to Silas' reclusive dead life earlier in the wilderness. However, it is not the only law that sustains and regulates Eliot's climax

Table 3. Raveloe Contrasts Lantern Yard in Eocsocial Diversity

\begin{tabular}{lllllllll}
\hline & Pages & Men & Women & $\begin{array}{l}\text { Social } \\
\text { Groups }\end{array}$ & $\begin{array}{l}\text { Incoming } \\
\text { people }\end{array}$ & $\begin{array}{l}\text { Outgoing } \\
\text { people }\end{array}$ & $\begin{array}{l}\text { Class/ } \\
\text { Occupation }\end{array}$ & $\begin{array}{l}\text { Religious } \\
\text { faith }\end{array}$ \\
\hline Raveloe & 175 & 31 & 20 & 12 & 6 & 0 & 17 & 3 \\
Lantern Yard & 10 & 5 & 3 & 3 & 1 & 8 & 5 & 1 \\
\hline
\end{tabular}


community. It must be balanced with the law of Nature, moral law and legislation, which restrain the desires and behaviors of individuals or groups.

Eliot constantly alludes to law of Nature, the Power that the universe manifests to us, or the Law of operations in an orderly universe or nature, the basis of which can be understood as the Platonian Form of the Good. It is essentially the chain of cause and effect endowed with moral implications. The wicked is eventually punished and the good are rewarded; even when a good person is in trouble, it is temporary. Squire Cass's house is kept in idleness and dissolution, without due constraints and discipline, and so it is destined to decline. By contrast, the "yeomen" are diligent and kind, and so they will be well-off and happy.

In some cases, the law of Nature is referred to as fortune or chance, verging on mystery. As Nancy Paxton convincingly argues, Silas Marner reveals Eliot's ontological interest in the irreducible "mystery" of creation, and that her characters respond psychologically to the mystery of the Unknown and find in it a source of the outward and inward laws which determine religious feelings and morality (Paxton, 2014). The novel embodies the mysterious law in many places. For the evil and diabolical Dunstan, there is a mysterious force leading him up to Silas's cottage to steal and finally to his own death in water; in comparison, the good-natured but morally flawed Godfrey manages to keep his reputation from being ruined by some unforeseen turn of fortune.

Despite Eliot's loss of faith as sudden and decisive as her conversion (Simpson, 1978), the law of Nature in Silas Marner is endowed with religious implications. This law is to be held in awe since there is wisdom of God in it. Eliot might have Proverbs 9:10-12 in mind: "The fear of the Lord is the beginning of wisdom." Eliot tells us that the Cass house have no fear and so declines out of dissipation and mismanagement. In other places, Eliot replaces the law of Nature with the more obviously religious "Providence". Eliot shows interest in regeneration of a lost soul, or in restoration of spiritual life in Silas, whose experiences suggest strong parallel to those of Job and provide strong evidence for a trace of Eliot's Christian humanism, a philosophy that combines Christian ethics and humanist principles. When he loses his money, Silas suspects that it is Providence that puts him in trouble. Likewise, it seems that Providence leads Eppie to his life and saves him. In the end, "Providence works wonderfully and mysteriously, calling the past to remembrance, turning sin and suffering into a path of salvation" (Fisch, 2013). The good Silas is rewarded with a filial daughter and his lost gold recovered. There is religious retribution in it.

However, Eliot poses two ways of faith in the two different communities. Many critics notice the difference between what Raveloe practices and the "faith" in Lantern Yard. One of Eliot's central concern is to warn of the dangers of blind faith such as held in Lantern Yard (Jackson, 2008). When Dane William persuades his brother in faith to decide on Silas's guilt by drawing lots in the name of God, their faith is in capricious chance rather than in Divine justice.
By contrast, Raveloe is not harsh or severe with regards to religious belief. It is a loose kind of belief. Eliot believes in a synthesis of Christian faith and atheistic humanism, "in which Christianity is stripped of dogma and its supernatural machinery but in which its emotional, humanitarian core is retained intact" (Simpson, 1978). She is especially interested in how one responds psychologically to religion and finds in it a source of religious feelings and morality. The religion that evokes and appeals to emotions and feelings, the religion where one finds emotional ties, is a more binding force than the religion of dogma.

Apart from the law of Nature, what also maintains order in Eliot's Raveloe is moral law. Raveloe is not a place where moral censure is severe. However, Eliot somehow believes in the necessity of moral rules to guard one from evil wishes. The Cass house is sustained on a long family history, restrained by a sense of decency, by the neighbors' gaze and moral appraisal, by moral codes and social conventions, and balanced by a respect for mutual contract. Godfrey's indulgence in his sexual instincts can only be carried out in city away from the gaze of the whole community.

Mutual contracts and covenants mean respecting the rights of each other, restraining desires and free will through negotiation and compromise, and bearing obligations to each other. An ethical person lives according to the mores of his community and accepts the responsibilities of his deeds. Silas Marner shows Eliot's credo of personal responsibility, since "Eliot posits the individual's sense of liability - his or her concern about producing harm in the world - as the most effective means for binding people to a common moral standard and in turn for giving structure to social relations" (Berger, 2000). On behalf of Eppie, Silas is willing to subscribe to the community and so he has a strong sense of responsibility and liability to conform to the mores of the community in order to establish efficient social relations. However, this sense of liability responsibility must necessarily contain reciprocity and mutuality, that is, responsibility and liability to one's fellow humans. Influenced by Hobbes, Eliot might well believe that "contracts and covenants result in obligetions between man and man, and the failure to perform, or make good on these obligations, plunges man back into the 'condition of war"' (Abitz, 2017). Although he hopes to adopt his own daughter Eppie, Godfrey negotiates with Silas instead of coercing. When he fails to have Eppie back, Godfrey accepts this punishment and makes every effort to make up. In Hobbesian terms, Godfrey "willingly engage in covenants and contracts with their citizens to strive towards peace" (Abitz, 2017). Through interaction and recognition, he is able to understand and share Silas's feelings and emotions.

As for the villagers, the working class in the community, moral codes and virtues are important as well. They are kind, simple, humble, helpful, and establish simple and close relationship with each other, which is totally different from that in the industrial Lantern Yard that features mechanization and erasing of humanity. The close relationship, seasoned with gaze and gossip, does not leave much room for privacy, and works as moral constraint to a certain extent. The villagers talk about Squire Cass's indulgence of his sons and their lack of morality. The gossip contributes to Eliot's "eager[ness] to castigate the 
class of squires for their dissolution and... failure to maintain moral principles" (Karl, 2007). In comparison, interpersonal relationship in the more industrialized city is loose, without much moral supervision. Godfrey is tempted in the city, secretly marries Molly and has a child with her, and Molly from the city is frozen to death during opium stupor on her way to salvation. Dunstan gambles and drinks in the city, ending up in death. Silas is greatly hurt in the anonymous city where his friend betrays him and plots on him, and where his fiancée never has an intimate relationship with him and finally abandons him. In short, the relationship in the industrial world is alienated and distorted.

In addition to moral rules and social conventions, legislation is also indispensable for an orderly society. The Rainbow is the place of moral supervision, but sometimes it is also like a small courtroom. The shop keeper functions as a mediator. People convene there like a jury when there is a dispute, and express their own opinions and try to come to a solution through discussion and negotiation. With common sense, reason and conscience, people reach an agreement under the mediation of the shop keeper. In addition, the court also plays its proper role. Raveloe also has its judicial system. When Silas' gold is stolen, people in Raveloe hand over the case to law by reporting it to the judge.

In summary, Eliot presents an orderly Raveloe that features principles of diversity and wholeness. Different kinds of individuals and groups form a community of good order governed by mutual contract and achieve check and balance with regard to desires and interests, freedom and responsibility. While Lantern Yard represents expansion of desires that inevitably leads to oppression and violence, infringement on the living space and interests of others, and death of the whole system in the end, Raveloe is a community that ultimately achieves unity of tolerance and constraints.

\section{Entropy and Principles of Mobility and Value Exchange}

Despite its ecological network that features diversity and dynamics between tolerance and order, a climax cannot be a completely isolated and closed system in case it might run the risk of running down because of increased entropy. Entropy, a thermodynamic concept that can be applied to closed systems of any size to measure the systems' degree of uncertainty or disorder, has become an important concept to evaluate environmental and ecological systems and their driving processes (Kleidon et al., 2010). The total entropy change of an ecosystem is equal to the sum of entropy flow generated spontaneously within the system and entropy flow caused by the system's exchange of material, energy, and information with the outside world. In an isolated and closed system, as the total entropy of the system increases, the system degenerates and becomes more and more chaotic and disordered, and its vitality weakens. In order to maintain its orderliness, the system needs to maintain exchange of material, energy, and information both within the system and with the outside world to decrease the total entropy of the system, and to lead to its self-renewal and sustain- able development. A climax does not mean that it is static; rather, it maintains equilibrium among energy flows, nutrient cycling and production. In this perspective, the entropy principle is closely related to resilience, recovery, and dynamic equilibrium of the system (Cushman, 2018). When applied to a society, this principle can check energy flow and value exchange both between the system and the external world, and and among individuals or communities within the system. A system must make full use of both local and incoming cultural resources with minimum waste in order to realize regeneration.

The communications between Raveloe and the outside world are reflected in its acceptance and absorption of outsiders. The Lammeter family come to Raveloe with their belongings. Because of their merits, adaptability, and management skills, the family are prosperous and have a promising future. The declining Cass family is saved from further decline through Godfrey's marriage with Nancy of the Lammeters.

As for Marner, he participates to a certain extent in the energy flow, "nutrient cycling", and information transmission of the "host" community, and establishes a mutually beneficial relationship with it. The key to his participation in the system is his adoption of Eppie of the Cass family, through which he overturns the meaning of "alien" or "wanderer" defined by the villagers, and becomes an important part of Raveloe, representing positive values. He sympathizes with Molly's suffering and brings this sympathy into Ravloe. In a way, Silas becomes the interface between the industrialized world and Raveloe, promoting healthy energy flow and information exchange. Ecologically, Silas establishes interactions with the working class in Raveloe, helping to create rich soil and good root system for the plant of Raveloe, contributing to its stable existence and growth.

In addition to communications with external world, information exchange and energy flow within Raveloe itself can be analyzed from several aspects. First, there are energy flow and values transformation among different social groups. In her portrayal of the declining Cass family, the rising Lammeter family, in her emphasis that Silas and his neighbors, the working class, have a promising future, Eliot shows a strong sense of social mobility. However, what is more important is the "nutrient cycling", or interactions, energy exchange and value transformation among social groups or strata. It is generally held that the group to which the Cass family belong should embody the values of the upper class: men should be noble, dignified and managing political or economic affairs in a reasonable way, and ladies should adhere to moral norms and be well cultured, humble and dignified. However, this group seems to increase in entropy. But fortunately, the community to which Silas belongs is truthful, courteous and dignified, full of vitality and hope. Eliot not only subverts the values that are supposed to define upper and lower classes, but also makes Eppie an integration of the excellent temperaments of the working class and the nobility, symbolizing interactions, energy exchange and values transformation among social groups, which reduces the entropy of the entire community.

The second aspect of information exchange and energy flow within the Raveloe community has to do with female and 
male groups. George Eliot subverts patriarchal values and highlights women's importance. For Eliot, woman can represent discipline and order, and maternal love. Nancy restores the Cass household to order and peace. She represents neatness, purity, and liberal orderliness. And the woman who represents maternity is Dolly. She is conscientious, kind, gentle, mild, patient, compassionate, eager to serve and willing to help.

Nevertheless, Eliot subverts the traditional maternal role of women. Nancy has her own ideas in domestic matters, but her greatest weakness is lack of real independence of mind. She compromises what is right or wrong in order to conform to what men expect of her. Her first moral failing lies in taking her husband's selfish thoughts to take back Eppie as her own. Another moral failing is class arrogance she shares with Godfrey that "decent family" must necessarily be happier than "poor family" and that the lower and poor cannot have the same affections and sensibility as the upper class do. She is as selfish as her husband.

As a counterexample, Priscilla is a pioneer in feminism. An independent and witty woman with common sense, Priscilla believes that if a female has property or can make a living on her own, she does not need to rely on man. Eliot hints at the plight of females in those days when most women have no property or cannot earn a living, and they have no way out but to rely on men. Through Priscilla, Eliot also criticizes men's greed, which reminds us of ecofeminist criticism of over-exploitation of natural resources by the patriarchal society and of men's insatiable desires that lead to war (King, 1989). Eventually, Priscilla manages the farm for her old father and becomes an independent woman both mentally and economically.

Despite her subversion of patriarchal values, Eliot does not hold female to be superior to male. She shows that men and women have diverse characteristics and roles to play against stereotypes. Eliot does not believe that values attached to social genders are fixed. Silas is qualified in his role of raising and nurturing a child essentially on his own, traditionally considered to be a maternal job. Priscilla is capable of running a business, traditionally considered to be man's job. Eliot shows spectrum of qualities and roles that a man or a woman can possibly have.

Raveloe as a climax is dynamic rather than a perfection. Eliot might be skeptical "about Spencer's assumption that individual development and social change are both defined by a clearly progressive improvement" (Paxton, 2014) since Silas experiences regression and Raveloe is flawed in many aspects. Many critics already note that Raveloe is not an ideal Wordsworthian community (Paxton, 2014). It is "rife with prejudice, about weavers, folk from other 'countries', tradition, religion and class, prejudices which contribute to Marner's isolation and misery" (Jackson, 2008). There are hierarchies of class and gender, primitive superstitions and misogyny and illiteracy that "characterizes their primitive religious and moral life"; the men and women have flaws of one kind or another, irresolution and profligacy of Squire Cass, moral dissolution and alienation of the Cass brothers, Godfrey's irresponsibility (Paxton, 2014), and there is also tragic death and robbery.
But in depicting Lantern Yard that goes to extinction and Raveloe with a promising future, Eliot anticipates the ecological theory that succession in the natural world might result in retrogressive succession, or it can also be developmental and progressive. From the perspective of ecological theory, Raveloe is a climax, or a developmental and progressive ecosystem. It is relatively independent but not completely closed up to outside world. It achieves interactions with the outside world to some extent. And within the community, there are certain exchanges and mobility, and value transformation is realized among different social strata or gender groups. In addition, its tolerance guarantees proper ecological niche for individuals and communities and ensures its diversity. This community maintains as low entropy as possible, maintains dynamic stability, and is capable self-regeneration.

\section{Reconciliation between Humans and Nature}

Ecosocial criticism does not fail to notice that an ecosocial climax must necessarily be situated in nature and nature-centered. Influenced by the biblical tradition and fable narrative, Eliot's flat characters and allegorical plots allow for "somewhat different standards of probability than a wholly naturalistic fiction could sustain" (Bloom, 2013) and encourage ecosocial interpretation of the allegorical meaning of the Eden image at the end of the novel. The elders are well supported and blissful, enjoying "an old age made mellow and hopeful through natural human relations" (Fairley, 1913), and the young, exemplified in Aaron and Eppie, enjoy healthy life and harmonious relationship in nature.

It is Eden built in nature and people are close to nature. Critics note that Silas Marner's "Worthworthian qualities-that unity of people and nonhuman elements is evident. Woods, hearth, quarry, plants, flowers, and seasons are all continuous with human activity, and underscore the interwoven quality of the lives and their environment" (Karl, 2007). The novel abounds in imagery arising from nature (Hardy, 2014). Eliot connects many things to non-human lives in nature: the children who make a joyous and lively house are nursery plants, and the disinherited son of a small squire, by contrast, is an uprooted tree.

In many places, Eliot intends to identify nature with maternity. The knowledge of nature is imparted to Slias by his mother so that he knows herbs that have healing effects. Eliot identifies maternity with the nurturing and healing ability of nature. The Lantern Yard community that makes Slias abandon this heritage allegorically means his separation from mother or from nature. By contrast, the rural world of Raveloe provides Silas access to the natural world that allows him to recover the repressed maternal in himself (Paxton, 2014), reaffirmed through his adoption of Eppie.

As the major builder of the Garden of Eden, Eppie's female identity is very important. She has what ecofeminism believes to be homogeneity with nature. She is close to nature and identified with nature. She wakes up the humility in Silas for him to love neighbors and to return to nature. She is also 
the one who desires the Garden, plans it and leads people around her to participate in its construction. In addition, Eliot endows this homogeneity between female and nature with divinity. She compares Eppie to an angel that leads people from the city of destruction, and even implies that Eppie has some quiet majesty or beauty that arouses a certain awe.

Another important figure in the garden is Aaron, who is engaged in cultivation and gardening. It is meaningful that Silas' adopted daughter should marry a gardener. He is steady and diligent, the archetypal Adam in the archetypal Eden. It reinforces the aura of divinity in the Garden that Aaron inherits the voice of his father to praise God in their garden, as Adam and Eve would be praising God in Eden.

The construction of the garden and life in it suggest farming life in nature that features manual work and resource conservation. Eliot has Eppie declare that she likes the working people and their ways of life. The simple meals at Silas' table in a house of warm love and productivity contrasts the extravagance and abundance at the Squire's table in a house of darkness and cold. The life of manual work contrasts with the affluent and easy life that brings the upper class a feeble appetite. It is consistent with the ecological ethics that humans should turn from exploiting and plundering nature to moderate development and utilization of nature in harmonious co-existence. Eliot speaks through Aaron that the land made use of wisely will not result in hunger, which anticipates contemporary ecofeminist attack on exploitation of natural resources and human greed.

The end of the novel presents the newlyweds in warm sun and among blooming flowers, symbolizing transformation from loss, pain, death of industrial world to life (regeneration) and love in nature. On the one hand, industrialization is an irresistible current, increasingly invading rural areas and taking up rural living space, resulting in an increasingly severe polarization between rich and poor. In this background, preserving a rural lifestyle in an ecosocial climax means conserving an ecological space for a life of self-reliance. On the other hand, the divine nature of the garden in the novel seems to imply that this natural way of life, with its focus on warm and loving human relationship in unity with nature rather than on hierarchical power, materials and money, is what pleases God. This may be what Eliot's idea of the "law of life": that human beings live with a humble heart in nature in awe for God. This unity of God, humans and nature that contrasts with the apocalypse of materialism, idolatry, alienation, and depletion of resources in the industrial world is possible only in an ecosocial climax.
With its promise of becoming Eden in nature, Raveloe climax represents the hope for a future in rural ecological environment.

\section{Discussions and Conclusions}

In the past few decades, increasing environmental awareness has brought ecocriticism and ecofeminism to the fore. However, while they make contribution to effecting change from human-centered to nature-centered thinking, they sometimes either tend to overlook the problems in human society itself, or unable to tackle the sources of environmental issues. This study proposes an ecosocial criticism in literature as an authentic and effective nature-centered approach that not only extends humanistic concerns and ethical thinking to the ecological world, but also learns from nature and from scientific study in ecology and environment science to seek ways to make sense of cultural and social problems, to contribute to a harmonious human relationship between humans and the natural world.

For this purpose, an ecosocial climax model that can be used in ecosocial criticism in literature is established based on such ecological concepts as biological chain, succession and climax community, and ecological niche, to analyze human communities to ensure protection of ecosystem. This model is used to evaluate the two communities in George Eliot's novel Silas Marner. Environment information of ecosocial system is extracted from the literary text for analysis. The results indicate sharp contrast between the Raveloe climax and Lantern Yard, as shown in Table 4. Raveloe demonstrates what contributes to a healthy ecological network: situated in nature and naturecentered, it features (1) equality and interdependence of individuals and of groups intersectioned with gender, class and occupation, and religion; (2) tolerance and diversity that welcome adaptability of the individual; (3) governance by Law of Nature, morality and legislation to guarantee check and balance; (4) dynamic equilibrium maintained through internal and external interactions and value exchange to ensure sustainable development in harmony with nature.

This interdisciplinary research does not simply analyze nature images and symbols and their thematic functions in literary works, as it would do in ecocriticism or ecofeminism. Rather, it is an effort to connect nature with culture through literary studies. On the one hand, as a critical study of literary works, it focuses on interrelated dimensions of ecology and ethics that other forms of knowledge tend to neglect, and in a way be-

Table 4. Raveloe Climax Contrasts with Lantern Yard

\begin{tabular}{|c|c|c|c|c|c|c|c|c|}
\hline & \multicolumn{2}{|c|}{ Ecological network } & \multicolumn{2}{|c|}{ tolerance inclusiveness } & \multicolumn{2}{|c|}{$\begin{array}{l}\text { complexity diversity } \\
\text { (class, gender, etc.) }\end{array}$} & \multicolumn{2}{|c|}{$\begin{array}{l}\text { Interdependence } \\
\text { mutuality }\end{array}$} \\
\hline Lantern Yard & $x$ & & $x$ & & $x$ & & $x$ & \\
\hline Raveloe & $\sqrt{ }$ & & $\sqrt{ }$ & & $\sqrt{ }$ & & $\sqrt{ }$ & \\
\hline & \multicolumn{3}{|c|}{ Law } & \multirow{2}{*}{\multicolumn{2}{|c|}{ Internal exchange }} & \multirow{2}{*}{\multicolumn{2}{|c|}{ External exchange }} & \multirow[t]{2}{*}{ Nature } \\
\hline & of Nature & moral law & legislation & & & & & \\
\hline Lantern Yard & $\sqrt{ }$ & $x$ & $x$ & $x$ & & $x$ & & $x$ \\
\hline Raveloe & $\sqrt{ }$ & $\sqrt{ }$ & $\sqrt{ }$ & $\sqrt{ }$ & & $\sqrt{ }$ & & $\sqrt{ }$ \\
\hline
\end{tabular}


comes complementary to detailed scientific research and works on parts of the socio-ecological system. On the other hand, it integrates ecological concepts and ideas into literary criticism to parallel natural world and the literary world, and to evaluate the fictional human world with knowledge about natural world acquired in scientific studies. In the calling for building collaboration of STEM fields (science, technology, engineering and math) to understand and solve some of the complex challenges of today and tomorrow (Sanders, 2009), the social studies, arts, and humanities shall not be excluded. This study is an effort to combine STEM with culture to form STEMc.

Because of this collaboration of fields, the ecosocial climax model proposed in this study can not only be applied to ecosocial criticism of fictional world in other literary works, but also lead to fruitful examination of human world. In the future research, specific and quantitative studies can be carried out on diverse cultures or societies to analyze them based on the ecosocial climax model proposed in this research and solutions might be found as to social problems such as cultural conflicts and violence. Overall, this research will improve our understanding of the dynamics of the social system, facilitate analysis of many social problems, enhance our awareness to embrace tolerance for diversity and to establish ecological social order, which will in its turn enhance environmental bonding and caring, and contribute to reconciliation between humans and nature, and ultimately, protection of ecosystem and nature.

Acknowledgments. This research work was funded by the National Social Science Fund of China (14BWW036). The authors are grateful to the anonymous reviewers for their comments and suggestions that helped improve this paper.

\section{References}

Abitz, D. (2017). Eliot and Hobbes: Finding Leviathan in "Hints on Snubbing" and "Janet's Repentance". Victorians J. Cult. Literature, 131, 13-25. https://doi.org/10.1353/vct.2017.0004.

Berger, C. (2000). When Bad Things Happen to Bad People: Liability and Individual Consciousness in Adam Bede and Silas Marner. Novel Forum Fiction, 33(3), 307-327. https://doi.org/10.2307/1346167.

Buell, L. (1995). The Environmental Imagination: Thoreau, Nature Writing, and Formation of American Culture. Harvard University Press, Cambridge.

Bloom, H. (2013) Introduction. Bloom's Modern Critical Interpretations, Silas Marner, in P. Loos (Eds). Infobase Publishing, 1-3.

Bookchin, M. (1993). What Is Social Ecology? Environmental Philosophy: From Animal Rights to Radical Ecology, in M.E. Zimmerman (Eds), Englewood Cliffs: Prentice Hall Inc., 354.

Chase. J.M. and Leibold, M.A. (2003). Ecological Niches: Linking Classical and Contemporary Approaches. University of Chicago Press, Chicago, USA. https://doi.org/10.7208/chicago/978022610 1811.001.0001.

Chen, Y., Cheng, S.Y., Liu, L., Guo, X.R., Wang, Z., Qin, C.H., Hao, R.X., Lu, J. and Gao, J.J. (2013). Assessing the Effects of Land Use Changes on Non-Point Source Pollution Reduction for the Three Gorges Watershed Using the SWAT Mode. J. Environ. Inf., 22(1), 13-26. https://doi.org/10.3808/jei.201300242.

Clements, F.E. (1936). Nature and Structure of the Climax. J. Ecol.,
24(1), 252-284. https://doi.org/10.2307/2256278.

Cushman, S. (2018). Editorial: Entropy in Landscape Ecology. Entropy, (20) 5, 314. https://doi.org/10.3390/e20050314.

Ding, X.W., Hou, B.D., Xue, Y., and Jiang, G.H. (2017). Long-Term Effects of Ecological Factors on Nonpoint Source Pollution in the Upper Reach of the Yangtze River. J. Environ. Inf., 30(1): 17-28. https://doi.org/10.3808/jei.201700370.

Eliot, G. (1967). Silas Marner, Penguin Books.

Estok, S.C. (2005). Shakespeare and Ecocriticism: An Analysis of "Home" and "Power" in King Lear. J. Australas. Univ. Language Literature Assoc., 103, 13-36. https://doi.org/10.1179/0001279058 05260537

Fairley, E. (1913). The Art of George Eliot in Silas Marner. Engl. J., 2(4), 221-230. https://doi.org/10.2307/800944

Fisch, H. (2013). Biblical Realism in Silas Marner. Bloom's Modern Critical Interpretations: Silas Marner, in P. Loos (Eds). Infobase Publishing, 45-62.

Folke, C., Hahn, T., Olsson, P., and Norberg, J. (2005). Adaptive Governance of Social-Ecological Systems. Annu. Rev. Environ. Resou., 30(1), 441-473. https://doi.org/10.1146/annurev.energy.30. 050504.144511

Glotfelty, C. and Fromm, H. (1996). The Ecocriticism Reader: Landmarks in Literary Ecology. Athens and London: University of Georgia, 107.

Hardy, B. (2014). Politics and Pastoral in Silas Marner. G. Eliot Rev, $45,17-21$.

Henson, E. (2011). Landscape and gender in the novels of Charlotte Brontë, George Eliot, and Thomas Hardy: the body of nature. Routledge.

Huang, G.H. and Loucks, D.P. (2000). An inexact two-stage stochastic programming model for water resources management under uncertainty. Civ. Eng. Environ. Syst., 17(2), 95-118. https://doi.org/10. 1080/02630250008970277.

Huang, G.H., Huang, Y.F., Wang, G.Q., and Xiao, H.N. (2006). Development of a forecasting system for supporting remediation design and process control based on NAPL-biodegradation simulation and stepwise-cluster analysis. Water Resour. Res., 42(6). ht tps://doi.org/10.1029/2005WR004006.

Jackson, C. (2008). "Affection towards a baseless opinion": Clare Jackson looks at Eliot's exploration of unquestioning belief in Silas Marner. Engl. Rev., 19(2), 34-37.

Karl, F.R. (2007). Introduction. Silas Marner in George Eliot (Eds), Signet Classics, i-xiii. https://doi.org/10.1007/978-0-387-46252-3_1

King, Y. (1989). Ecology of Feminism and the Feminism of Ecology. Healing the Wounds: The Promise of Ecofeminism, in J. Plant (Eds), New Society Publishers, 18-28.

Kleidon, A., Malhi, Y., and Cox, P.M. (2010). Maximum entropy production in environmental and ecological systems. Philos. Trans. R. Soc. Lond., Ser. B: Biol. Sci., 365(1545), 1297-1302. https://doi. org/10.1098/rstb.2010.0018.

Kopnina, H., Washington, H., Taylor, B., and Piccolo, J. (2018). Anthropocentrism: More than Just a Misunderstood Problem. $J$. Agric. Environ. Ethics, 31, 109-127. https://doi.org/10.1007/s1080 6-018-9711-1.

Li, Y.P. and Dang, C.L. (2006). The Research Progress of Climax Community in Forest. J. Yunnan Univ., 28, 298-303.

Li, Y.P., Huang, G.H., and Nie, S.L. (2010). Planning water resources management systems using a fuzzy-boundary interval-stochastic programming method. Adv. Water Resour., 33(9), 1105-1117.

Manolache, S., Nita, A., Ciocanea, C. M., Popescu, V.D., and Rozylowicz, L. (2018). Power, influence and structure in Natura 2000 governance networks. A comparative analysis of two protected areas in Romania. J. Environ. Manage., 212, 54-64. https://doi.org/ 10.1016/j.jenvman.2018.01.076. 
Mazzeno, L.W. and Morrison, R.D. (2017). Victorian writers and the environment: ecocritical perspectives. Routledge, New York.

Mies, M. and Shiva, V. Ecofeminism. (1993). London and New Jersey, Zed Books.

Nangong, M.F., Zhu, H.M., Wu, T.T., and Lu, L.T. (2011). Ecofeminism: Literary Interpretation of Gender, Culture and Nature. Social Sciences Academic Press, Beijing, 102.

Nassiri, H., Özgür K., and Gül, S. (2016). A Hermit: A Kierkegaardian Reading of George Eliot's Silas Marner. J. Intern. Soc. Res., 9(47), 553-560. https://doi.org/10.17719/jisr.2016.1400.

Nihorimbere, V., Smargiassi, and Thonart (2011). Beneficial effect of the rhizosphere microbial community for plant growth and health. Biotechnol. Agron. Soc. Environ., 15(2), 327-337.

Oppermann, S. (2013). Feminist Ecocriticism: A Posthumanist Direction in Ecocritical Trajectory. International Perspectives in Feminist Ecocriticism, in G. Gaard, S.C. Estok, and S. Oppermann (Eds), Routledge.

Pastori, M., Udias, A., Bouraoui, F., and Bidoglio, G. (2015). A MultiObjective Approach to Evaluate the Economic and Environmental Impacts of Alternative Water and Nutrient Management Strategies in Africa. J. Environ. Inf., 29(1): 16-28. https://doi.org/10.3808/jei. 201500313.

Paxton, N.L. (2014). George Eliot and Herbert Spencer: Feminism, Evolutionism, and the Reconstruction of Gender. Princeton University Press, Princeton.

Sanders, M. (2009). STEM, STEM Education, STEMmania. Technol, Teacher, 68(4), 20-26.

Simpson, P. (1978). Crisis and Recovery: Wordsworth, George Eliot, and Silas Marner. U. Toron. Q., 48(2), 95-114. https://doi.org/10.31 38/utq.48.2.95

Stephens, A. (2013). Ecofeminism and Systems Thinking. Routledge, New York. https://doi.org/10.4324/9780203767283

Su, L.Y., Christensen, P., and Liu, J.L. (2013). Comparative Study of Water Resource Management and Policies for Ecosystems in China and Denmark. J. Environ. Inf., 21(1), 72-83. https://doi.org/10.38 08/jei.201300234.

Tong, S.T., Sun, Y., and Yang, Y.J. (2015). Generating a Future Land Use Change Scenario with a Modified Population-Coupled Markov Cellular Automata Model. J. Environ. Inf., 19(2): 108-119.

Van der Valk, A. G. (2014). From Formation to Ecosystem: Tansley's Response to Clements' Climax. J. Hist. Bio., 47, 293-321. https:// doi.org/10.1007/s10739-013-9363-y.

Wang, X. (2006). Ecologism and Humanism: Their Way of Reconciliation. J. Shenzhen Univ., 5, 99-105.

Whittaker, R.H. (1953). A Consideration of Climax Theory: The Climax as a Population and Pattern. Ecol. Monog., 23(1), 41-78. https: //doi.org/10.2307/1943519.

Williams, D. (2017). Victorian Ecocriticism for the Anthropocene. Victorian Literature Cult., 45, 667-684. https://doi.org/10.1017/S1 060150317000080.

Xie, Y., Crary, D., Bai, Y., Cuis, X., and Zhang, A. (2019). Modeling grassland ecosystem responses to coupled climate and socioeconomics influences in multi-spatial-and-temporal scales. J. Environ. Inf., 33(1) 37-46.

Yang, W. and Yang, Z.F. (2014). Evaluation of Sustainable Environmental Flows Based on the Valuation of Ecosystem Services: a Case Study for the Baiyangdian Wetland, China. J. Environ. Inf., 24(2): 90-100. https://doi.org/10.3808/jei.201400276.

Woo, J.H., An, S.M., Hong, K., Kim, J., Lim, S.B., Kim, H.S., and Eum, J.H. (2016). Integration of CFD-Based virtual sensors to a ubiquitous sensor network to support micro-scale air quality management. J. Environ. Inf., 27(2), 85-97. https://doi.org/10.3808/jei.20 1500314.

Zapf, H. (2008). Literary Ecology and the Ethics of Texts. New Literature Hist., 39(4), 847-868. https://doi.org/10.1353/nlh.0.0066

Zhang, J., Liu, L.R., Shi, X.C., Wang, H., and Huang, G. (2017). Environmental Information in Modern Fiction and Ecocriticism. J. Environ. Inf., 30(1), 41-52. https://doi.org/10.3808/jei.201700374.3 